\title{
James Steuart: \\ as questões heterodoxas de um economista político conservador
}

Maria Mello de Malta Professora da UFRJ

\section{Palauras-chave}

James Steuart, economia política, perspectiva heterodoxa.

Classificação JEL B12, B31, B51.

Key words

James Steuart, political economy, heterodox perspective.

JEL Classification B12, B31, B51.

\section{Resumo}

Este trabalho busca apresentar as principais questões trazidas pela obra de James Steuart ao pensamento heterodoxo atual. Os trabalhos de Steuart sobre economia política possuem a marca da dualidade. Tal dualidade em seu pensamento o condenou ao ocaso em sua época e à vala comum do mercantilismo por parte da história do pensamento econômico tradicional, mas também foi a riqueza de sua obra. Este artigo procura explorar essa característica dual da obra de Steuart para conectá-la com as releituras e reabilitações de seu pensamento promovidas pela heterodoxia atual. Este estudo se insere, portanto, no movimento que busca ampliar o conhecimento da visão de Steuart sobre o funcionamento da economia e sobre a economia como ciência, para evidenciar que essa disciplina, desde a sua concepção como ciência autônoma, já dispunha de alternativas embebidas nas importantes divergências metodológicas referentes aos modos de pensar a natureza das ciências sociais.

\section{Abstract}

This work intends to present the main heterodox questions brought up by James Steuart's thought. Steuart's works on political economy have the sign of duality. This sign condemned this work to ostracism during this life time and labeled him as mercanlist in the history of economic thought. This article uses the duality in his work to connect it with the recent research recovering his initial ideas. This study is a part of a movement that seeks to spread the knowledge of Stenart's visions about the economic process and political economy as a science to put forward the interpretation that political economy in its origin is submerged in important divergences about scientific perspectives. 


\section{1_Introdução}

Sir James Steuart (1712-1780) era um aristocrata e diplomata escocês com grandes ambições de poder (Skinner, 1999). Após se qualificar como advogado (1735-1740), engajou-se em um projeto muito comum para jovens da aristocracia de sua época: tomar contato com outras culturas e modos de pensar por meio de longas viagens pelos países da Europa.

Nos cinco anos em que esteve no continente, viajou pela Holanda, Alemanha, França, Espanha e Itália. Na sua estadia na Itália, tomou contato com os jacobitas, grupo com o qual se envolveu politicamente desde então. Os ideais jacobitas (aliança católico-conservadora) estavam associados à restauração do absolutismo e a crítica ao "credo" liberal. Os jacobitas almejavam o retorno ao trono inglês da linhagem de James II - os Stuarts -, cuja deposição pela Revolução Gloriosa determinou o fim do absolutismo e a instalação de uma monarquia parlamentar. Em 1745, Steuart foi um dos grandes articuladores da Revolução Jacobita, que pretendeu levar o neto de James II - Charles Edward - ao trono da Inglaterra. O envolvimento político de Steuart com uma revolução fracassada contra a coroa britânica determinou seu exílio por 17 anos.
Especula-se que a relação entre Steuart e os Jacobitas tenha tido como pano de fundo principal seu projeto pessoal de poder (Skinner, 1999). Uma carta de sua tia Mrs. Mure, compilada por Chamley (1965a), juntamente com outros documentos, revela uma nuance privada interessante sobre a relação de Steuart com o projeto Jacobita:

[...] se aquela revolução tivesse sido vencedora, conforme ele desejava, ele teria sido o primeiro homem do governo. Quando seu Príncipe estava em Edimburgo ele [Steuart] era consultado sobre tudo, ele escreven o $M a$ nifesto, e várias outras coisas em jornais públicos, além de ter sido enviado como embaixador à França em busca de auxílio. (Carta de Mrs. Mure, in: Chamley, 1965a)

Foi no exílio (1746-1763), inicialmente na França, que Steuart iniciou seus estudos sobre economia política. Conforme Redman (1996), foi em Tübingen na Alemanha, que escreveu seu primeiro trabalho sobre temas de economia política. ${ }^{1}$ Também no período em que esteve em Tübingen, escreveu os três primeiros livros de sua obra principal, os seus Principles of Political Economy: being an Essay on the Science of Domestic Policy in Free Nations. In which are particularly considered Population, Agriculture, Trade, Industry, Coin, Interest, Circulation, Banks, Exchange, Public Credit, and Taxes, ${ }^{2}$ que fo-
1 "Dissertation into the doctrine and principles of money, applied to German coin" foi publicado em 1761.

2 O texto original de Steuart não está disponível em sua versão integral em nenhuma biblioteca brasileira. Felizmente, o desenvolvimento tecnológico permitiu a autora o acesso ao original via internet no site http://www.marxists.org/ reference/subject/economics /steuart/index.htm. Por outro lado, esse tipo de arquivo, por não ser fac-simile da obra original, não possui número de página para que as referências bibliográficas das citações textuais de Steuart sejam realizadas nas bases adequadas. Optamos, nessas condições, em fornecer a melhor referência possível que é o capítulo em que se insere cada citação.

Vale dizer que os capítulos de Steuart em geral são curtos, o que facilita qualquer busca mais interessada. 
$\ldots \ldots \ldots \ldots$ 3 O trabalho de referência é Sen (1947), que posteriormente escreveu sua tese de doutorado e um livro sobre a obra de Steuart. Podemos destacar também o artigo de Stettner (1945) publicado no Quartely Journal of Economics. ram finalizados no seu retorno a Escócia, para ser publicados em 1767.

Os trabalhos de Steuart sobre economia política possuem a marca da dualidade. Sua perspectiva científica misturava a necessidade de pensar abstratamente com o realismo e a concretude de um profissional prático. Essa característica tinha relação com sua posição de aristocrata e consultor político e econômico de um pretenso governo paralelo. A verdade é que toda a construção filosófica, teórica e analítica steuartiana é um reflexo dessa perspectiva. Nada em sua contribuição para a economia política deixava de ter fortes raízes na realidade. $\mathrm{O}$ autor sempre revisitava as instituições e relações vigentes na economia em que vivia para criar seus conceitos e desenvolver seus argumentos. Foi usando esse método de relação íntima entre teoria e realidade que formulou concepções e princípios muito avançados para sua época. Mesmo tendo sido silenciado pela vitória do liberalismo, aqueles desenvolvimentos eram tão ricos que acabaram por ressurgir como questões importantes após várias gerações (com Marx, List e Keynes, por exemplo).

Foi também a proximidade com a realidade que dificultou para Steuart a percepção de nuances menos permanentes do sistema econômico e seu processo de mudança, determinando que sua teoria tivesse a marca das instituições e relações sociais de sua época. Steuart ainda carregava forte dualidade em sua perspectiva teórico-filosófica. Identificava a importância crucial do Estado na determinação da dinâmica econômica e defendia o absolutismo, sendo um antiliberal, ao mesmo tempo em que seus trabalhos buscavam explicar a sociedade usando o indivíduo como foco central. Isso fez com que reconhecesse no indivíduo a fonte de emanação dos desejos e das motivações que organizavam a sociedade, mas também negava a existência de uma ordem social espontânea com base exclusiva na ação dos indivíduos. Esse autor reconheceu no Estado o grande operador econômico e social e não acreditava em um funcionamento harmônico da economia se estivesse entregue aos próprios meios ou ao mercado.

A dualidade de seu pensamento o condenou ao ocaso em sua época e à vala comum do mercantilismo por parte da história do pensamento econômico tradicional, mas também foi a riqueza de sua obra. A perspectiva antiliberal e institucional de seu trabalho estimulou releituras, que, por sua vez, geraram reabilitações pela heterodoxia. Tais estudos têm sido realizados desde os anos 40 do século XX, no bojo da crítica keynesiana à teoria marginalista. ${ }^{3} \mathrm{~A}$ crítica de Keynes articulava-se com a crise econômi- 
ca de 1929 e o questionamento do liberalismo nos anos 30 , justificando a recuperação do pensamento steuartiano. Atualmente há uma nova tendência de trabalhos que visam à reabilitação da obra de Steuart. ${ }^{4}$ Atribuímos tal tendência às questões cada vez mais presentes acerca dos problemas do crescimento e do desenvolvimento econômico e a sua possível relação com o alinhamento dos países centrais ao neoliberalismo - forma atual e extremada de liberalismo.

Historicamente os esforços de recuperação do pensamento de Steuart o buscaram como um instrumento de questionamento da teoria e da política econômica ortodoxa. $\mathrm{O}$ movimento atual, realizado no âmbito da heterodoxia, explora várias vertentes de sua obra. Assim, parece-nos interessante apresentar e organizar as principais questões trazidas à tona pela obra steuartiana, que, mesmo abortadas pelo projeto liberal clássico iniciado por Adam Smith (1776), permaneceram relevantes até os dias de hoje. Este estudo se insere, portanto, no movimento que busca ampliar o conhecimento das visões de Steuart sobre o funcionamento da economia e sobre a economia como ciência, para evidenciar que essa disciplina, desde sua concepção como ciência autônoma, já dispunha de alternativas embebidas nas importantes divergências referentes aos modos de pensar a natureza das ciências sociais.

\section{2_O processo de reabilitação de Steuart pela heterodoxia: a linha tênue entre a realidade e o desejo}

Antes de partirmos para a reabilitação das questões e do trabalho de Steuart, é necessário reconhecer as dificuldades desse processo. Como descreve Meek (1971), o aumento da tendência moderna a recuperar certos autores antigos se relaciona com a observação de que:

A teoria raramente acompanha a história: lacunas sérias surgem e se acumulam, embora permaneçam mais ou menos ignoradas pelos ortodoxos até que um acontecimento de força telúrica (a baixa de 1929, a publicação da General Theory de Keynes, o discurso de Khruschev sobre Stalin) obriga a reconhecer-se que a teoria desligou-se da realidade. Segue-se que o reinado da complacência e do dogmatismo inicia a marcha para o esquecimento, e o homem começa a perguntar-se se certas idéias mais antigas, rejeitadas pela ortodoxia corrente, não teriam, afinal de contas, algum valor (Meek, 1971, p.12).

Por outro lado, existem os problemas importantes normalmente contidos nos processos de reabilitação. Como alerta Meek,

infelizmente poucos reabilitadores modernos escapam à tentação de utilizar o pro- $\cdots \cdots$ 4 Tortajada (1999) reúne uma série de artigos apresentados em uma conferência sobre Steuart realizada no Museu da Revolução Francesa no Chatêau de Vizille, em 1995. Blaug (1991) apresenta uma coletânea de artigos sobre a obra de Steuart produzidos desde 1945 até 1981 e apresentados em importantes revistas de economia em língua inglesa. 
$\cdots \cdots$

5 Há quem afirme, como é o caso de Kobayashi (1999), que Steuart pertencesse a uma tradição científica mais aristotélica (no sentido de ter sempre laços próximos com a realidade), enquanto Smith caminha na direção de desenvolvimento de um método mais platônico (no sentido de caminhar para uma formulação totalmente referida ao campo das ideias). Nossa interpretação se apoia uma posição diametralmente oposta também encontrada em Redman (1996) e Skinner (1965) e afirma que Smith e Steuart estavam muito próximos do ponto de vista metodológico, sendo ambos parte de uma tradição do método histórico, apesar de expressarem teoricamente visões de mundo diferentes, o que dá origem a contribuições muito distantes do ponto de vista da interpretação do fenômeno econômico. cesso como base para uma re-interpretação completa da história do pensamento econômico, [....] em conseqüência, corre-se sério risco de perder o distanciamento crítico quando se analisa antigos sistemas teóricos (Meek, 1971, p.12).

É necessário, portanto, considerar o contexto histórico particular em que cada teoria foi proposta, para sermos capazes de encontrar as raízes de algumas das ideias atualmente em voga, levando em consideração suas especificidades históricas, e não cair na tentação de reescrever a história do pensamento com base em tais origens, determinando uma interpretação anacrônica.

Nesse sentido, procurou-se não perder de vista a perspectiva histórica quando analisamos a obra de Steuart. Um trabalho da natureza do nosso só tem razão de ser do ponto de vista, cada vez mais atual, de que o estudo da história do pensamento econômico é necessário tanto para nos dar senso de humildade e estabelecer pedigrees respeitáveis para as novas teorias, como também - e muito mais importante - para nos dar a direção correta na tarefa de tirar a economia do impasse em que se encontra em algumas áreas hoje em dia.

A obra de Steuart possui várias interfaces com ideias, conceitos e visões de mundo que foram descartadas em sua época e só foram retomadas pela teoria econômica no século XX. Sendo assim, a magia e o interesse de sua obra estão em recolocar a divergência estrutural do pensamento econômico e localizá-la em sua origem.

Não podemos, porém, perder de vista a recomendação cuidadosa de Meek sobre manter o distanciamento crítico. É fato que a vitória do liberalismo, que disputava com o pensamento conservador do século XVIII, foi tão avassaladora, em todos os campos, que as ciências sociais, em sua natureza de ser cortadas pelas visões de mundo de seus autores, não poderiam ter escapado desse processo. O trabalho de Steuart foi vítima da derrota dos conservadores. Nunca um trabalho tão extenso e dedicado fora tão rapidamente eclipsado como foi o caso dos Principles de Steuart diante da obra $A$ riqueza das nacõoes de Smith.

Por outro lado, não é possível discordar de Meek e Skinner quando afirmam que não foi apenas o viés conservador de Steuart que condenou seu trabalho ao ocaso. Segundo esses autores, Smith apresentou uma proposta superior em vários outros sentidos: seu texto tinha uma leitura mais fácil, seu sistema era completo analiticamente, sua percepção da sociedade que se formava era mais acurada, e Smith se aproximava mais do padrão científico ditado pelas ciências naturais. ${ }^{5}$ 
Entendido em seu contexto, Steuart foi um cientista social conservador, que não conseguiu executar um projeto tão isento quanto gostaria, na medida em que seu conservadorismo o impediu de ver a sociedade que se formava e direcionou seu olhar para a forma social anteriormente existente, cuja permanência era seu desejo. O economista escocês não percebeu claramente que os problemas vivenciados pela sociedade em que vivia eram típicos de um período de transição, quando o velho e o novo convivem formando um sistema que não consegue se afirmar, parecendo estar em uma crise insuperável, e não diante do nascimento de algo novo.

Steuart pensava em como solucionar os problemas econômicos de um Estado absolutista e atribuía boa parte das dificuldades vigentes aos descaminhos do liberalismo. Desta forma, identificava no Estado a força necessária para superar os problemas do crescimento econômico colocados pelo desenvolvimento crescente do modo capitalista de produção. Steuart não acreditava que, ao deixar a economia livre de intervenções, emergiria espontaneamente dos interesses individuais uma ordem social harmônica. No pensamento steuartiano, o Estado deveria intervir para orientar o autointeresse dos indivíduos em prol do interesse público maior. A obra steuartiana talvez seja a últi- ma que carregue a visão da economia do ponto de vista do poder do Estado e, nesse sentido, a última a ser capaz de compreender o poder econômico do setor governamental, antes da revolução keynesiana.

Recuperar o pensamento de Steuart não significa, portanto, refundar a história do pensamento econômico, mas destacar suas controvérsias de origem. A contribuição desse autor à economia política é tão extensa como sua obra principal e dá margem às mais diversas leituras, dada a sua natureza dual; porém seu processo de reabilitação pela heterodoxia tem tomado como linha de exploração central sua teoria da acumulação. Tal destaque se justifica não só por sua centralidade no trabalho do autor e por suas particularidades, como também por ser um fundamento para uma discussão heterodoxa que reintroduz o Estado de forma ativa no desenvolvimento econômico e critica a visão liberal. Sua valorização da intervenção do governante destaca não apenas o papel do Estado como gerador de investimento, mas também como incentivador ao consumo improdutivo, postura rara entre os clássicos.

Essas particularidades de sua visão sobre acumulação reafirmam a dualidade de sua obra, inclusive do ponto de vista analítico, e nos fornecem elementos para compreender como, por meio de seu con- 
servadorismo, trata de temas relevantes para a heterodoxia de hoje. Além disso, permitem-nos explorar, sem perder a perspectiva histórica, suas principais contribuições à economia política sem a necessidade de desejá-lo com precursor de qualquer conceito ou teoria moderna, respeitando os limites de um processo de reabilitação de um autor do século XVIII.

\section{Entre a realidade mercantilista e o pensamento clássico}

Sabendo que Steuart escreveu boa parte de sua obra no continente e que teve forte influência dos trabalhos de economia que estavam sendo realizados na França e na Alemanha, compreende-se a forte influência em sua obra de um contexto

\footnotetext{
6 As noções de classes sociais de Steuart (explicitadas na nota de rodapé 16), bem como suas concepções não convergentes de lucro, entre as quais incluem lucros obtidos em trocas desiguais, são limites analíticos para descrever o capitalismo, que serão superados por outros autores da tradição clássica. Vale ressaltar que esses limites, como já dissemos, são reflexo do tipo de
}

econômico diverso daquele da ilha (GrãBretanha). Desta forma, uma série de pequenos atrasos analíticos ${ }^{6}$ de Steuart em relação ao pensamento clássico posterior se justifica menos como miopia e mais como uma leitura mais próxima da realidade econômica existente. Ao mesmo tempo, foi a perspectiva de um cientista que escrevia de fora do território da economia central do período (Grã-Bretanha $)^{7}$ que o permitiu questionar o processo de desenvolvimento e a importância do Estado em seu estabelecimento e sua dinâmica.

Essa perspectiva excêntrica deu-lhe a possibilidade de enxergar que o desenvolvimento econômico ocorre em fases e possui forte relação com a estrutura produtiva e institucional existente, além de não ser um movimento automático ou determinístico do sistema. A percepção de Steuart era que são sempre necessárias políticas ativas para garantir o desenvolvimento, inclusive no que se refere à relação com outras nações. $\mathrm{O}$ autor percebia tão claramente a existência de fases de desenvolvimento que se dedicou a elaborar uma sistematização de suas características. É interessante notar que na sua concepção a importância das relações internacionais nesse processo era tão forte que os títulos das fases do desenvolvimento estão associados com as possibilidades de obtenção de vantagens com 
o comércio exterior - infant trade; foreign trade e inland trade. ${ }^{8}$

Para Steuart o país teria de possuir uma visão estratégica que compatibilizasse seu grau de desenvolvimento das forças produtivas com suas políticas de comércio, para não acabar por sucumbir à concorrência dos outros países. Esse autor pensava a existência de duas possibilidades de comércio externo: comércio passivo ou comércio ativo. O comércio passivo é aquele em que a população do país se engaja por encontrar dificuldades para a obtenção de certos produtos no país. O comércio ativo é aquele em que o país se engaja em uma política ativa de estímulo ao consumo nos países vizinhos dos bens produzidos internamente.

Segundo Steuart, o comércio passivo tende a ser prejudicial à nação, na medida em que traz produtos de fora cuja competição inibe a tentativa de produção interna

de bens equivalentes. Além disso, em regime de comércio passivo, o país está submetido à política ativa de comércio de outro país, cujo interesse é expandir seu excedente, inclusive por meio da compra de produtos básicos nos países com que transaciona. $\mathrm{O}$ ideal é que se coordene a economia internamente para que possa entrar de maneira lucrativa no comércio ativo.

$\mathrm{Na}$ questão do comércio internacional, fica, então, claro um importante aspecto não liberal de seu pensamento sobre economia. Não pertencer à matriz liberal não deveria ser suficiente para excluir um autor da escola de pensamento clássica e defini-lo como mercantilista. Como então ocorreu a identificação de Steuart como um autor do mercantilismo?

A história do pensamento econômico tradicional aceitou a definição de mercantilismo apresentada por Adam Smith

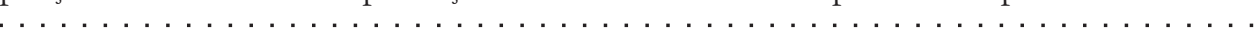

8 O estágio de infant trade infant trade é a base para se representa os primórdios do desenvolvimento de uma economia mercantil. Steuart indica que, no estágio de infant trade, o objetivo do comércio é fazer circular o excedente, de forma que os possuidores desse excedente sejam providos com bens de luxo e os que não possuem o excedente tenham acesso a ele, sendo capazes de obter sua subsistência. O período de estabelecer o comércio externo, mas o país ainda se encontra praticamente fechado para as trocas internacionais. É vedada a entrada de produtos estrangeiros, e apenas será exportado um pequeno excedente industrial, se esse começar a existir antes da maturidade competitiva do setor industrial da economia. Foreing trade é o estágio em que o país já possui sua indústria forte o suficiente para concorrer internacionalmente. Neste estágio, a nação aproveita as condições construídas no estágio de infant trade para comerciar internacionalmente. $\mathrm{O}$ comércio estabelecido deve ser fruto de uma política ativa de exportação de bens de luxo e importação de bens básicos. Finalmente, Inland trade reflete uma economia já bastante desenvolvida em termos industriais, porém que perdeu sua competitividade internacional, seja graças ao desenvolvimento relativo de outros países, seja pela sua riqueza interna. Neste caso, retorna-se ao padrão de comércio de infant trade, contudo em condições muito melhores de dar conta da demanda interna. 


\footnotetext{
9 Toda a história do pensamento econômico tradicional inscreve Steuart como o "último dos mercantilistas", como é o caso de quase todos os livros-textos $\mathrm{da}$ área, que mencionam Steuart, entre os quais citamos o de Eric Roll (1948), o de Porto Carreiro (1975) e o mais recente Samuels, Biddle e Davis (2003).

10 Aspromourgos (1996), Aspromourgos (2000), Yang (1994) e Tortajada (1999) são as principais referências para esta abordagem.

11 Para uma discussão sobre o conceito de economia política clássica, ver Malta (2005a).
}

no capítulo I do livro IV de $A$ riqueza das nações (1776). Naquele capítulo Smith buscou criticar o que chamou de "princípio do sistema comercial ou mercantil", que é a visão de que a riqueza de um país tenha qualquer relação com a quantidade de ouro e prata que esse tenha em suas fronteiras. Seu argumento procurou mostrar que tanto ouro quanto prata são apenas representações materiais de valor e riqueza, como qualquer outra mercadoria. Alternativamente, Smith argumentou que a riqueza de uma nação resulta do tamanho do seu produto anual em relação ao quanto é necessário para o reproduzir, ou seja, um país será mais rico quanto maior for o seu produto excedente. Contudo, aquele capítulo de Smith ainda possuía dois objetivos importantes. De um lado, procurava criticar, para além do próprio conceito de riqueza ligado ao acúmulo de metais preciosos, o argumento de que o enriquecimento estaria ligado a ganhos nas trocas desiguais. De outro lado, desejava apontar os malefícios que o controle sobre os fluxos externos de ouro e prata e, portanto, sobre o comércio internacional, trariam para o processo "natural" de desenvolvimento de uma nação.

Desta forma, o conceito comum de mercantilismo se baseia nessas questões levantadas por Smith. Assim, quando se classifica um autor de mercantilista, quer se di- zer que: 1) não possui uma teoria do valor e distribuição adequada, na medida em que os lucros proviriam de trocas de não equivalentes; 2) seu conceito de riqueza é baseado no acúmulo de metais preciosos sem a preocupação com a geração de alimento para a população; e 3) sua visão de comércio internacional, na medida em que é intervencionista, compromete a capacidade "natural" da nação em crescer.

É interessante notar que Steuart não incorre em nenhum dos dois primeiros "erros" dos autores mercantilistas, porém certamente tinha uma visão sobre comércio internacional bastante intervencionista. Conforme levantamos inicialmente, a estratégia de comércio internacional, segundo Steuart, tinha de ser pensada para se articular favoravelmente com o projeto de crescimento econômico e desenvolvimento interno das forças produtivas do país. Foi esse o "pecado" que o colocou na vala comum dos pensadores mercantilistas.

Há, porém, todo um trabalho atual que rejeita esta visão a respeito da obra de Steuart. De acordo com esses estudos, ${ }^{10}$ Steuart é um autor da escola clássica. Para classificar Steuart com um autor clássico, todavia, não basta afirmar que sua obra não cabia no conceito de mercantilista de Smith; é necessário ainda enquadrá-lo em alguma concepção de economia clássica. ${ }^{11}$ 
Da perspectiva sraffiana, a escola clássica de pensamento está relacionada com a análise da economia utilizando como noção central o conceito de excedente, não possuindo nenhuma relação atávica com o pensamento liberal. Nesse sentido, quando Aspromourgos (1996) afirma que em Steuart,

o excedente é entendido da maneira clássica típica, como a diferença entre o produto bruto agregado da sociedade e as quantidades agregadas das mercadorias direta on indiretamente requeridas para se obter 0 consumo de subsistência da força de trabatho ou população (Aspromourgos, 1996, p. 419).

Esse autor constrói a ponte necessária para a ligação entre Steuart e a economia política clássica. ${ }^{12}$

Para reforçar a filiação de Steuart à escola de pensamento clássica, é ainda necessário ratificar que a noção de excedente em Steuart tem as mesmas implicações sobre o seu conceito de riqueza ${ }^{13}$ que a dos clássicos. Esse autor comungava da noção analítica dos clássicos de que o aumento da riqueza de uma nação tem como base a geração crescente de excedente, exatamente como Smith argumentou contra os mercantilistas e como toda a escola clássica viria a fazer. Além disso, o produto social com que Steuart trabalha também é analiticamente dividido nas mesmas três classes de renda que os clássicos posteriores, ou seja, salários, lucros e rendas. ${ }^{14}$

Também na questão dos lucros, é fácil identificar o elemento suficiente para mantê-lo na abordagem clássica, e esse é bastante claro: apenas lucros gerados a partir de um aumento do trabalho ou engenho no processo produtivo seriam capazes de gerar crescimento da riqueza social. Sendo assim, lucros que têm como origem as trocas desiguais não são capazes de ampliar o excedente. Isso significa que Steuart não propagou a ideia de que a fonte dos lucros,
12 Em seu trabalho, Steuart se filia à tradição clássica de pensamento citando William Petty como uma das suas principais referências no campo econômico. Ao contrário de Smith, que não era dado a citar outros autores no campo da economia - como demonstra carta sua a

\begin{abstract}
Putlteney, datada de 1772, [em que] diz: "Tenho sobre o livro de Sir James Steuart a mesma impressão que você. Sem tê-lo jamais mencionado, épara mim motivo de orgulho que todos os princípios falazes contidos no livro de Steuart encontrem clara e indubitável refutação no meu" (Meek, 1958, p. 293) - Steuart cita Petty até como a origem
\end{abstract}

das noções de trabalho produtivo e trabalho improdutivo, também utilizadas por Smith, mas sem referência àquele autor.

13 Para uma discussão mais detalhada sobre este tema, ver Malta (2001).

14 Há, porém, diferenças importantes na concepção de Steuart sobre economia; uma delas é a concepção

das classes sociais.

Destacamos essa diferença porque, apesar de utilizar as mesmas classes de renda, Steuart extrai implicações diferentes sobre a distribuição, na medida em que possui outra concepção de classe social. 
que fariam parte do excedente, pudesse ser a troca de não equivalentes. ${ }^{15}$

Diante dessa argumentação que insere Steuart na escola de pensamento clássico, devemos retornar ao ponto de partida e nos perguntar se o único elemento que o colocou fora do campo da economia política clássica, segundo a história do pensamento econômico tradicional, foi a vitória da concepção de Smith a respeito do que seriam os fatores que colocariam um autor no campo do sistema mercantil.

Efetivamente o papel fundamental que a realidade econômica da época e dos lugares em que viveu tinha em seu trabalho lhe trouxe algumas limitações. Um reflexo importante da influência da perspectiva histórica sobre seus conceitos analíticos está em sua concepção das classes sociais. ${ }^{16}$ Suas classes sociais não foram concebidas tendo a propriedade sobre os meios de produção como eixo central. O trabalhador steuartiano já não possui a terra em que produz, mas ainda é proprietário de seus instrumentos de trabalho. A posse dos meios de produção não está separada do trabalho produtivo. Dessa forma, a renda percebida por cada agente econômico não será fundamentalmente associada à propriedade, com exceção do caso da terra. Nesse contexto, Steuart também não identificou o surgimento de uma nova classe social na agricultura e na indústria - a classe que empregava capitais na contratação de trabalho assalariado e que, em consequência, colhia os lucros que estavam em uma proporção mais ou menos regular ao volume de capital empregado - a classe dos capitalistas. Talvez por isso o lucro em Steuart não seja associado exclusivamente a uma remuneração do capital, não sendo proporcional ao seu emprego.

\footnotetext{
15 Steuart, todavia, possui vários conceitos de lucro, entre os quais se encontram lucros provenientes de trocas desiguais; contudo, esse tipo de lucro é caracterizado de forma diferente daquele auferido a partir da produção. Para uma discussão mais aprofundada sobre o tema, ver Malta (2001).

16 As classes sociais em Steuart são:
}

1) Os farmers (fazendeiros) são os responsáveis pela produção agrícola. Seu consumo é composto de produtos agrícolas e produtos industriais. Os produtos agrícolas fazem parte da subsistência física. Já os produtos industriais podem ser tanto de subsistência política como de luxo;

2) Os industrious free-hands (trabalhadores industriais) trabalham na indústria, sendo responsáveis pela produção industrial. Seu padrão de consumo, em um estágio inicial, é mais simplório, pois consomem basicamente bens de subsistência física. Ainda assim, Steuart admite a possibilidade de existência de um pequeno consumo de bens industriais (portanto de subsistência política ou de luxo) por essa classe; 3) Os proprietários de terra são outra parte dos free-hands, que auferem sua renda de direitos sobre o excedente da produção agrícola. Seu padrão de consumo é mais exuberante, possuindo uma componente básica de bens agrícolas, enquanto trocam a maior parte de sua renda por bens de luxo e de subsistência política. 
Desta forma, Steuart não concebeu seu estudo de economia no contexto de um sistema já definitivamente capitalista. Portanto, apesar de poder ser pensado como um autor clássico, Steuart carrega o fardo dos conceitos historicamente datados que levaram a muitos autores da história do pensamento econômico tradicional fazer leituras mercantilistas de sua obra.

\section{4_Entre a teoria e a prática}

A forte relação de sua produção teórica com sua prática política foi aquilo que trouxe para a obra de Steuart um sabor ultrapassado em alguns conceitos, mas foi também origem de sua riqueza analítica, bem como abriu uma discussão peculiar sobre a noção da economia como ciência. Skinner (1965) destaca que, apesar de Steuart, como toda a tradição científica escocesa do século XVIII, identificar o indivíduo como o centro da análise e a experiência como a base para a formulação da teoria, esse autor possuiu adicionalmente a particularidade de enfatizar as limitações da economia como ciência. Na concepção de Steuart, a limitação da economia como ciência pura só pode ser superada valendo-se de uma abordagem histórica. Não existe um sistema econômico abstrato que possa dar conta de explicar completamente os fenômenos econômicos e sociais, objeto dessa ciência.

Steuart tinha total consciência da ambição de sua obra. Não foi por acaso que ele abriu o prefácio dos Principles com a seguinte frase:

\section{É com grande receio que apresento ao pú- blico esta tentativa de reduzir a principi- os, e transformar em uma ciência regular os complexos interesses da politica (po- licy) nacional.}

$\mathrm{O}$ autor teria pretendido formular sua ciência com base na dedução, procurando, de acordo com sua experiência no exílio, ao conhecer uma série de economias diferentes e se despindo de todo e qualquer preconceito, ser capaz de distinguir leis gerais que definissem uma nova ciência. ${ }^{17}$ Vejamos também a citação abaixo, extraída ainda do Prefácio dos Principles (1767):
Este [trabalho] vai um ponto mais longe que coletar e organizar alguns elementos relativos aos temas mais interessantes de politica (policy) moderna, [...]. Os princi- pios deduzidos de todos os tópicos parecem toleravelmente consistentes; e o todo é uma linha de raciocinio por meio da qual des- crevi a conexão de todos os temas o mais fielmente que pude: mas sendo a natureza do trabalho uma dedução de princípios,

\footnotetext{
17 'O prefácio dos Principles de" Steuart é uma grande nota sobre seu o método.
} 
não uma coleção de instituições, aproveitei as oportunidades que meu raciocínio colocou em meu caminho, para conectar cada princípio [...] com cada parte da investigação à qual se referisse [...]

É fato, porém, admitido pelo próprio Steuart, que ele não pretendia elaborar um sistema no sentido do conceito científico utilizado pela tradição francesa de sua época. Steuart rejeita "aquilo que os franceses chamam de Sistemas”, afirmando que

estes são nada mais que uma cadeia de conseqüências contingentes, derivada de máximas fundamentais, adotadas, talvez, sem muito cuidado. Tais sistemas são meramente conceitos; eles ludibriam o entendimento e apagam o caminho para a verdade (Steuart, 1767, prefácio).

Isso significa dizer que, apesar de destacar a possibilidade e a necessidade de se encontrar princípios gerais e universais para explicar o fenômeno econômico, Steu-

18 Há uma importante produção que indica uma inspiração de Hegel na obra de Steuart na formulação do método dialético. Um exemplo pode ser visto em Ege (1999), que referencia também Chamley (1963) e Chamley (1965).

19 Com base em Silveira (1994), podemos identificar Steuart como um autor que percebe a indeterminação de Sênior, ou

seja, que não pretende trabalhar no campo do desenvolvimento econômico baseando-se em teoria pura, reconhece a necessidade de se descer no nível de abstração e incorporar questões históricas e institucionais específicas para que se produza uma explicação adequada do fenômeno. art discordou que tais princípios devam ser articulados para formular um sistema que crie sua total independência explicativa em relação à realidade. A complexidade da realidade tem de ser sempre "revisitada" pelo cientista para a formulação de explicações apropriadas. ${ }^{18}$

Isso leva Skinner (1965) a afirmar que a visão de Steuart reflete os procedimentos, mas não a ênfase, típica do pensamento moderno, uma vez que ele "coloca tanta ênfase nas limitacõoes da economia científica como na necessidade de tratar a economia como ciência'19 (Skinner, 1965).

A proposta de Steuart foi conceber a produção como fator organizador das relações sociais, sendo esse um princípio capaz de responder e formular perguntas próprias e, nesse contexto, dar lugar a uma disciplina que nasce da prática, da história, para posteriormente ganhar uma formulação teórica e acadêmica.

Outra implicação importante da relação entre a teoria e a realidade histórica trabalhada por Steuart é não aceitar que a concepção do indivíduo do século XVIII, fruto da sociedade da livre concorrência,

"que aparece desprendido dos laços naturais que, em épocas históricas remotas, fizeram dele um acessório de conglomerado bumano limitado e determinado (Marx, 1857, p. 25-26), 
possa ser o homem em seu "estado puro". Ao contrário, tal indivíduo é um resultado histórico. Nesse sentido, Steuart trabalha com uma noção de indivíduo diferente daquela da tradição liberal abrindo o espaço para a compreensão de uma série de contradições na relação entre indivíduo e Estado em sua obra. Ao mesmo tempo, essa outra concepção sobre o indivíduo possibilita uma visão articulada e interessante de ser recuperada entre essa unidade e a unidade social.

\section{5_Entre o indivíduo e o Estado}

A tradição do pensamento científico-filosófico do século XVIII reflete a principal questão da modernidade: afastar o divino da origem da explicação da sociedade e centrá-la no homem. Steuart situa-se perfeitamente nessa tradição. $\mathrm{O}$ indivíduo é a origem dos desejos e das motivações que organizam a sociedade; porém Steuart não enxerga a causa ou o mecanismo que possam vir a gerar espontaneamente uma ordem econômica ou social a partir dos desejos individuais.

A ordem para Steuart não é autoinstituída; é a consequência da construção de hierarquias, poderes e instituições que refletem, limitam e redefinem os interesses individuais. Com base nessas ideias, Steuart fornecerá uma interpretação para o funcio- namento da economia que tem como mola mestra o autointeresse do indivíduo, mas esse precisa ser mediado pelo Estado e pelas relações de produção para ser capaz de determinar o funcionamento da economia e uma ordem harmônica da sociedade. Sendo assim, há limites bastante claros ao autointeresse e o mais evidente está na figura do governante (que representa o Estado).

Steuart deixa claro que o governante não pode ser conduzido pelo autointeresse. Pensar autointeresse em relação a essa figura cria a noção de "espírito público". É o espírito público que guia o governante. Por outro lado, essa é uma questão que diz respeito estritamente ao governante. Os governados não precisam ter esse tipo de sentimento, a não ser mediado pelo "autointeresse" e não há nada que os harmonize espontaneamente.

Assim, compete ao governante conferir ao Estado nacional um status quo que interesse a sua população. Se o povo se entender agindo em interesse próprio, ele terá forte motivação para reproduzir o status quo definido pelo "plano do governante". Há, portanto, um plano do governante que "manipula" o autointeresse dos cidadãos com o objetivo de gerar e manter determinada ordem.

Esse ponto da obra de Steuart questiona a ideia liberal de que o autointeresse é 
o mediador das leis da natureza para dar regularidade ao sistema econômico, ou que exista uma mão invisível que harmonize o caos potencial dos interesses individuais e os oriente ao bem estar coletivo. De fato, no trabalho de Steuart, a regularidade do sistema econômico é dada pela atuação do Estado orientando a produção. Se existe uma mão que oriente os interesses individuais essa é bem visível e é a "mão" do Estado.

Uma forma rica de interpretar a obra de Steuart é pensar que o princípio básico da organização de uma sociedade seja a viabilização da subsistência necessária para sustentar uma população crescente. A subsistência é parte do autointeresse; porém sua base material é a produção. Essa interpretação é totalmente consistente com o foco da análise steuartiana sobre o desenvolvimento econômico na evolução do processo de produção de subsistência da população. $\mathrm{Na}$ descrição do processo de desenvolvimento, tanto os métodos de produção da subsistência se complexificam (enquanto se tornam mais eficientes), como a própria subsistência vai incorporando novos padrões de consumo, determinando uma inter-relação entre o autointeresse dos indivíduos e o "plano" do governante que gera a dinâmica do sistema.

Supomos, então, que é pela sua explicação para o desenvolvimento da eco- nomia considerar o indivíduo, mas não ser baseada em uma lógica que emana exclusivamente dele que Marx (1857) destacou Steuart como um autor que escapou da "ingenuidade" (p. 26) dos cientistas sociais do século XVIII, que imaginavam que o homem moderno, isolado, independente do meio, formulado como objeto científico no século XVIII, fosse o ser humano em seu "estado puro". Marx afirmava que o homem é um animal social e como tal "só pode isolar-se em sociedade", isto é, o conceito de homem "livre" do século XVIII surge em um contexto em que as relações sociais atingem seu mais alto grau de desenvolvimento, não sendo, de forma nenhuma, independente dessas.

Do nosso ponto de vista, é esse entendimento steuartiano do funcionamento da economia que o afasta da tradição liberal e cria um interessante ponto de contato com a heterodoxia do século XX. Steuart supõe que a economia não era capaz de se desenvolver efetivamente se entregue aos próprios meios. Todo o seu entendimento da dinâmica econômica identificava a necessidade de um maior ou menor grau de intervenção, a depender do estágio de desenvolvimento das forças produtivas e do padrão de consumo, para que a economia pudesse crescer. Steuart poderia, portanto, ser pensado como parte de um caminho que se 
abre para uma perspectiva mais heterodoxa que compreende que a ação do indivíduo, além de limitada, está mediada pelas instituições, pelas regras e pelo Estado na determinação do funcionamento da economia.

\section{6_Entre o Estado e o mercado}

Não há como deixar de perceber uma implicação direta da forma com que Steuart concebe a relação entre indivíduo e Estado: não sobra muito espaço para o mercado. Contudo, não é possível imaginar que um autor que trabalhe o conceito de autointeresse de forma tão central exclua totalmente a ideia da existência de um dinamismo próprio da economia.

A relação entre Estado e "mercado" se apresenta no estudo do processo de acumulação elaborado por Steuart para descrever o crescimento econômico e a necessidade do Estado nesse processo. Conhecer tal instância do pensamento de Steuart é fundamental para a compreensão de como um atraso analítico tão grande como a falta de uma teoria da taxa de lucro e da noção de concorrência capitalista pode gerar um trabalho relevante para o estudo da dinâmica da economia capitalista.

$\mathrm{Na}$ verdade, Steuart desenvolveu seu argumento de acumulação por um caminho em que o processo de investimento ${ }^{20}$ não guardava relação com a determinação da taxa de lucros. O investimento, no trabalho steuartiano, é o resultado de decisões dos fazendeiros e do governo. Os fazendeiros são motivados pela intenção de consumir novidades de luxo, e o governante investe de acordo com o "plano ${ }^{21}$ " que possui para o desenvolvimento econômico. O objetivo privado, portanto, é o consumo e não o lucro concebido apenas como valorização do capital empregado. Já o objetivo público é promover as condições para desenvolver o país. O "plano" do governante inclui investimento direto na produção de bens de luxo para o estabelecimento da indústria e para a manutenção do equilíbrio entre os setores. Outro aspecto da atuação do Estado sob o "plano" é o gasto em consumo dos bens de luxo, com o mesmo objetivo de garantir a reprodução do setor que desperta o interesse dos fazendeiros em produzir mais bens de subsistência: a indústria. Nenhuma menção à taxa de lucro é feita. A taxa de lucro só surge no debate sobre distribuição, não possuindo qualquer papel na teoria da acumulação de Steuart. Não é o lucro que estimula a verve produtiva no sistema steuartiano, ${ }^{22}$ deixando de fora da dinâmica a noção de concorrência capitalista.

Da mesma forma que os clássicos, Steuart pensa na economia em termos de 20 A palavra "investimento" não é mencionada nos dois primeiros livros dos Principles (1767), em que Steuart apresenta sua teoria do crescimento e acumulação. $\mathrm{O}$ processo de investimento, porém, está claramente incluído no seu argumento.

21 É Steuart quem se refere ao planejamento do Estado para o desenvolvimento como "plano do governante".

22 Talvez seja isso que leve alguns autores modernos a permanecer considerando esse autor como um mercantilista, em vez de compreender sua obra como trabalho denso que tem como objetivo entender a economia como se apresentava naquele período histórico. 
um sistema de trocas de mercadorias, um circuito onde o objetivo é a obtenção de produto. Ainda assim, a maior parte deles atribui à concorrência por mais lucro o papel dinâmico do sistema. No caso de Steuart, contudo, não é a obtenção de mais lucro, que move o sistema. $\mathrm{O}$ que move o sistema é o Estado. ${ }^{23}$

$\mathrm{O}$ que justifica a produção de um excedente crescente é a manutenção da subsistência de uma população crescente. Para Steuart, o tamanho e o bem-estar da população são as medidas de performance da atividade econômica e o referencial para a avaliação da competência do governante. ${ }^{24}$ Sendo assim, o "príncipe" tem interesse em que o excedente seja ampliado e elaborará um "plano econômico" que viabilize a execução dos meios necessários para a obtenção desse fim.

No esquema steuartiano, o soberano deve mobilizar o autointeresse (selfinterest) de

23 Neste ponto ele difere de forma fundamental de seu contemporâneo Smith e dos clássicos subsequentes que enxergam no mercado a solução para o problema econômico. A operação do mecanismo de mercado nesse caso se dá através do processo de unificação das taxas de lucro. Discutiremos isso mais adiante.
24 Um trabalho interessante
sobre essa visão de Steuart é
apresentado por Gislan (1999).
25 "Devo agora supor que estes princípios estão bem entendidos.
Desejos incentivam ao trabalho,
trabalho aumenta a oferta de
alimento, mais alimento aumenta
números [população]: a próxima
questão é como esta população pode
ser bem empregada?" (Steuart,
1767 , livro I, cap. XI).

seus cidadãos para engajá-los na produção de excedente. $\mathrm{O}$ autointeresse do indivíduo steuartiano, porém, não é estimulado a partir da indicação da obtenção de mais lucro. $\mathrm{O}$ autointeresse desse indivíduo é socialmente constituído. Baseando-nos em argumentos de Kobayashi (1999) e Eagly (1961), podemos afirmar que Steuart pensava a acumulação partindo dos desejos dos indivíduos; esses desejos mobilizavam seu espírito de trabalho e isso dava lugar ao processo de enriquecimento da nação. ${ }^{25}$ Sendo assim, a chave da questão é identificar a fonte estruturadora dos desejos, já que os desejos constituem-se na base do autointeresse.

Eagly (1961), para organizar sua análise, formula a seguinte pergunta: por que os indivíduos trabalham em uma sociedade livre? A resposta de Steuart tem duas bases: a propriedade privada da terra e a aspiração a certo nível de consumo. $\mathrm{O}$ "efeito aspiração" está relacionado com o "espírito da população", sendo esse "baseado sobre um conjunto de opiniões recebidas relativamente a três pontos: moral, governo e hábitos" (Steuart, 1767, livro I, cap. II). Segundo Kobayashi (1999), considerar o "espírito da população" é o caminho de Steuart para a incorporação da história em seu método de análise, dado que, embora tenha tentado encontrar os princípios gerais que regem a economia, tinha a certeza de que esses não seriam apli- 
cáveis diretamente à execução de política econômica sem a mediação necessária. ${ }^{26}$

Sendo assim, objetivando realizar seu "plano econômico", o soberano vai organizar a atuação do Estado de forma a obter o resultado econômico mais coerente com seus interesses. Para alcançar seus interesses, porém, o governante tem de mobilizar o autointeresse de cada um de seus súditos. O grande problema que o governante tem de enfrentar para assegurar a manutenção de um excedente crescente na economia seu interesse principal - é garantir uma superação permanente do que Steuart identifica como os limites ao crescimento de uma nação. Como veremos a seguir, tais limites encontram seu mecanismo de superação na mobilização do autointeresse da população. É nesse âmbito que articula os interesses individuais com os limites ao crescimento tendo o mercado como operador econômico.

Os limites ao desenvolvimento econômico na visão steuartiana são o limite técnico e o limite social. O limite técnico é um limite do lado da oferta, que, estando ligado ao desenvolvimento tecnológico, tem dois aspectos: 1) o puro e simples desenvolvimento das forças produtivas; e 2) o compasso na evolução da produtividade dos setores produtivos.

O limite social é um limite do lado da demanda, que se baseia no peso do con- sumo de luxo na economia. Esse tipo de gasto tem como papel fundamental criar condições para o crescimento da população e da nação, sem ter efeito sobre a ampliação de capacidade produtiva na economia. Mas esse limite também tem ligação com questões de oferta na economia, na medida em que, no esquema de Steuart, para demandar é necessário ofertar. É, porém, apenas a demanda de luxo dos fazendeiros - a classe responsável pela produção de excedente - que tem impacto direto sobre o crescimento do produto. ${ }^{27}$

Desta forma, pode-se perceber que, no argumento steuartiano, os principais mecanismos para estimular o crescimento em uma economia estão ligados à capacitação tecnológica (desenvolvimento das condições técnicas de produção) e à forma da expansão da produção em sua relação com a demanda final (padrões de consumo e investimento).

Diante desses limites e sabendo que o autointeresse do indivíduo é socialmente constituído, Steuart propôs dois caminhos por meio dos quais o governante vai atuar para assegurar o crescimento econômico: 1) mantendo o compasso entre os setores produtivos, inclusive através de investimento direto; e 2) garantindo a formação de padrões de consumo cada vez mais elaborados em sua população.

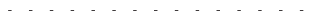
26 Silveira (1999) traça as linhas gerais de sua obra destacando os problemas em todos os níveis da profissão de economista causados pela Indeterminação de Sênior, conforme definida na nota 19 Essa questão trazida por Steuart é um reconhecimento típico (e raro)

da Indeterminação.

27 Como os fazendeiros produzem os bens básicos da economia, o excedente de sua produção é a base necessária para o aumento dos gastos produtivos. 
$\cdots \ldots \ldots$

28 Esta não é uma

comparação no sentido amplo, já que o esquema de Sraffa

(1960) se refere claramente a

uma economia capitalista, não possuindo qualquer dúvida sobre a importância da obtenção de lucro para a caracterização e manutenção do sistema. Steuart, conforme já discutimos, não produz uma teoria tão clara nesse aspecto. A comparação pretendida é relativa à independência reprodutiva do setor de básicos em relação ao setor de não básicos, e da agricultura de Steuart em relação à indústria.

29 É necessário ter em mente que, na indústria do período de Steuart, os trabalhadores tinham o domínio de toda técnica produtiva. Assim, o papel que atualmente é cumprido pelo engenheiro e pelo trabalhador especializado era representado pela mesma pessoa normalmente referida por Steuart como especialista.
O estímulo à elaboração do padrão de consumo na economia é uma resposta ao limite social ao crescimento. O limite social é fruto da inexistência de um mecanismo espontâneo que estimule o autointeresse dos produtores de excedente a expandir sua produção, deixando bastante claro que não há espaço para uma dinâmica instituída pelo mercado. Sem esse estímulo e considerando que pela forma com que Steuart concebeu os setores produtivos conferiu à agricultura um status semelhante ao setor produtor de bens básicos, ${ }^{28}$ e que só na agricultura se produz excedente, a dinâmica do sistema fica dependendo de um elemento externo a ele. Desta forma, é do interesse do governante estimular o consumo de luxo nos agricultores. Para que os agricultores consumam luxo, é necessário que desejem luxo. A forma que o soberano vai estimular o padrão de consumo é por meio de exemplo, uma espécie de imposição social ao consumo para a identificação de classe e riqueza. A outra condição necessária para o estabelecimento do consumo de luxo dos fazendeiros é a existência de um setor produtor de bens de luxo. É, então, da elaboração do padrão de consumo do agricultor que se garante a viabilidade do setor industrial.

A intervenção direta do Estado no âmbito produtivo se faz necessária para su- perar o limite técnico ao crescimento, porque o progresso técnico só se justifica a partir do interesse em ampliar o excedente, e esse interesse, na concepção de Steuart, é o foco econômico fundamental do Estado. Desta forma, o soberano tem de patrocinar a introdução de outras técnicas de cultivo que aumentem a produção de excedente e liberem braços da agricultura, deixando mão de obra disponível para ser aplicada no desenvolvimento de um setor de luxo. A existência desse setor também é considerada indicador de progresso técnico para Steuart, uma vez que ele cria a possibilidade de desenvolver a demanda dos agricultores por luxo, falando de perto ao seu autointeresse. A introdução do setor industrial também é fruto de intervenção governamental. A instalação da indústria no país significa que o governo vai se comprometer com um conjunto de políticas econômicas que envolvem comprar no exterior as máquinas necessárias para tal produção, atrair do exterior os melhores especialistas em cada técnica produtiva ${ }^{29}$ e até mesmo comprar os produtos dessas indústrias, enquanto o padrão de consumo interno ainda não estiver totalmente constituído.

A formação da indústria deve ser seguida de perto pela constituição dos hábitos de consumo de luxo entre os produtores de excedente. O motivo para isso é 
que a inter-relação entre setores se dá principalmente via consumo, não havendo dependência mútua em termos produtivos. Só a indústria depende da agricultura para se reproduzir, mas a agricultura é um setor totalmente autossuficiente. Assim, a superação do limite técnico tem de ser acompanhada pela superação do limite social, para que se mantenha uma estrutura econômica com dois setores produtivos (a agricultura e a indústria) em crescimento.

Neste ponto do argumento, há um reconhecimento da necessidade em se compatibilizar oferta e demanda de bens para garantir o crescimento. Assim, não podemos dizer que Steuart não identifique a necessidade de um mercado para a distribuição da produção. Ao contrário, esse mercado é tão necessário que, na sua ausência, deve ser constituído pelo Estado para dar vazão ao movimento dinâmico da economia. Nesse sentido, a questão de Steuart não é pensar o Estado como substituto ao mercado, mas ter certeza de que o mercado não é capaz de instituir a necessária harmonia expansionista ao sistema. A economia não é capaz de criar espontaneamente as motivações para sua sustentação e ampliação. Para o autor, não existe tal coisa como um mecanismo de mercado que garanta o funcionamento do sistema e dele derive uma ordem social estável.

\section{7_ Entre a demanda efetiva e a lei de Say}

Não reconhecer a existência de uma ordem espontânea derivada do mercado foi o primeiro passo de Steuart para a constituição de uma teoria da acumulação que prescindisse das noções de lucro e concorrência. Esse mesmo passo o colocou diante do problema da falta de demanda como obstáculo ao crescimento. Esse é um importante ponto de contato entre o trabalho de Steuart e os formuladores do princípio da demanda efetiva no século XX e talvez por isso outra interpretação muito comum da contribuição de Steuart à economia política o localiza, antes de Malthus ${ }^{30}$ como um precursor do princípio da demanda efetiva. Todavia, será que as recomendações de Meek lembradas no início deste texto nos permitiriam chegar a essa conclusão sem maiores considerações?

A questão da determinação do nível do produto na teoria clássica surge, como sabemos, no bojo da explicação dos mecanismos necessários para compreender a ligação entre a teoria do valor e distribuição e a teoria da acumulação. Sabemos também que a questão da determinação do nível do produto só ganha importância para os clássicos com base em Ricardo, apesar de ser um caminho necessário para o prin-
30 Sobre Malthus e o princípio da demanda efetiva, ver Malta (2005b). 
cipal objetivo daqueles autores: conhecer o processo de enriquecimento de uma nação.

Steuart não é diferente de seus contemporâneos. Não há em seu trabalho uma proposta explícita de uma teoria do produto; porém, foi uma convenção da história do pensamento econômico associar autores clássicos com o uso da lei de Say. Pode-se discutir o quanto isso é correto e o quanto isso está associado à leitura keynesiana do problema da teoria do produto. Pretendese, no entanto, seguir as recomendações de Meek e dar curso a uma discussão diferente e motivada pelos trabalhos de Yang (1994) e Aspromourgos (1996), que possuem visões distintas sobre a participação de Steuart no desenvolvimento de uma teoria do produto que culminou na formulação do princípio da demanda efetiva.

Yang (1994) trabalha no sentido de retomar, em meados dos anos 90, o argumento de uma literatura, iniciada no final dos anos 40 do século XX, que coloca James Steuart como precursor do princípio da demanda efetiva. Os trabalhos de Sen ("Sir James Steuart's general theory of employment, interest and Money" - 1947) e Chamley ("Sir James Steuart inspirateur de la "Théorie Générale" de Lord Keynes" 1962) estão na origem dessa interpretação.

Por outro lado, o trabalho de Aspromourgos (1996) apresenta a interpretação de que a conexão entre Steuart e os pensadores clássicos o inclui na tradição de pensamento de determinação do nível de produto segundo a lei de Say.

A questão que propomos é de outra ordem. Sabe-se que, a menos de Ricardo, nenhum outro autor clássico apresentou um trabalho totalmente consistente com a lei de Say. Steuart não foi diferente. Mas, além de não ter apresentado um argumento totalmente consistente com a lei de Say, ele elabora uma série de explicações para o mecanismo de acumulação, que, ao desacreditar a existência de uma tendência espontânea do mercado à harmonia, acaba propondo soluções para o crescimento compatíveis com a questão da demanda efetiva. Vejamos, então, como o problema se apresenta no pensamento steuartiano.

O circuito econômico de Steuart é construído com base em três classes sociais (farmers, industrious free-hands e proprietários de terras), cada uma com seu padrão de consumo específico e com sua atividade econômica ou fonte de renda particular. $\mathrm{O}$ padrão de consumo estabelecido por cada uma delas é o que vai gerar demanda efetiva (effectual demand), no sentido clássico, para o produto de ambos os setores da economia. Como é o consumo que motiva a produção, então, também esse será o determinante do novo investimento, ou seja, só 
faz sentido investir para aumentar a produção caso se deseje consumir mais.

Indicar que o consumo é a motivação exclusiva da produção é uma diferença marcante entre Steuart, seus contemporâneos e os clássicos posteriores, pois, como afirma Ricardo,

ninguém produz a não ser para consumir ou vender, e jamais se efetua uma venda a não ser com a intenção de comprar outra mercadoria que possa ser imediatamente utilizada [consumo] ou possa contribuir para a produção futura [investimento] (Ricardo, 1986, p. 197-198).

Assim, os clássicos já tinham clareza a respeito da intenção de investir, enquanto em Steuart isso não aparecia como uma decisão primária, apenas como uma consequência de uma motivação maior: consumir. Além disso, como já destacamos, Steuart não aponta o lucro e a concorrência entre os capitais como os elementos dinâmicos do sistema; portanto, em sua obra, é só o consumo que explica o crescimento da economia.

A dualidade no sistema steuartiano pode ser observada tomando-se por base o raciocínio a seguir. Considerando que cada classe tem um padrão de consumo próprio, que vai se transformar em demanda por bens de consumo ou por bens de investimento, de acordo com as circunstâncias específi- cas da economia e da sociedade, podemos concluir que, a depender da distribuição da renda entre as classes sociais, teremos um sistema mais propício a um tipo de gasto direto ou a outro. ${ }^{31}$ Ao mesmo tempo, isso não indica se o sistema efetivará menor ou maior nível de acumulação, ${ }^{32}$ já que não há uma valoração a priori de que tipo de gasto gera mais riqueza. De fato, é necessária a intervenção do Estado nesse processo para garantir um equilíbrio entre esses gastos, de forma a privilegiar a maior taxa de crescimento possível para o excedente.

O Estado de Steuart cumpre o mesmo papel da lei de Say nos clássicos posteriores, a saber: é ele quem garante a realização completa do produto. A solução pelo Estado reflete, portanto, o reconhecimento do problema da demanda efetiva. Steuart, porém, enxerga no excedente do setor agrícola como a condição necessária para o crescimento da economia, e o novo investimento, mesmo não sendo motivado pela busca de maior lucro, é financiado pela abstenção ao consumo. Sendo assim, o autor não chega a formular a concepção de que o investimento é o determinante da poupança, mantendo-se na linha clássica tradicional de pensamento.

Isso nos leva a concluir, mais uma vez, na direção da existência de uma dualidade em sua obra, em que o seu atraso ana- $\cdots \cdots \cdots \cdot \ldots$ 31 Entretanto, sabemos que independentemente de esse tipo de gasto ser em investimento ou em consumo, poderemos observar impactos importantes e diferentes sobre a acumulação.

32 Isso dependerá do funcionamento do multiplicador e do acelerador que só serão desenvolvidos em termos analíticos e conceituais no século XX. 
lítico equivaleu à remoção dos antolhos do crescimento movido apenas pelo investimento; todavia, não rompeu os padrões do pensamento sobre o financiamento do gasto.

Podemos, então, localizar Steuart na origem genealógica da questão da demanda efetiva, na medida em que, por mais que o excedente no setor agrícola seja a condição necessária para o crescimento da economia, não é a condição suficiente. Não é o tamanho do produto potencial que determina o produto efetivo, já que existe a possibilidade de os fazendeiros decidirem não investir mais na ampliação ou na manutenção do excedente, se não tiverem em vista novos produtos cujo consumo os interesse. O consumo improdutivo é uma contrapartida importante da produção de excedente. Mas é fundamental lembrar que esse resultado é fruto da ausência de um mecanismo do tipo smithiano, no qual o capital, em busca da maior taxa de lucro possível, migra entre os setores, dando curso ao mecanismo de mercado e ajustando a composição do produto. Por outro lado, não há como não enquadrá-lo na linha de pensamento clássica tradicional no que se refere ao financiamento do gasto.

Desta análise surge uma questão importante: o que exatamente torna um autor seguidor do princípio da demanda efetiva? A resposta a essa pergunta já foi dada por muitos e não há um consenso em relação a ela.
Dadas as observações que apresentamos sobre o processo pelo qual Steuart determina o tamanho e a forma de crescimento do produto, podemos conceber que seu trabalho seja compatível com o princípio da demanda efetiva baseando-nos no argumento a seguir. Considerando que o princípio da demanda efetiva seja o princípio de que a demanda agregada possa ser insuficiente para absorver o produto gerado a partir do uso normal da capacidade instalada (Garegnani, 1983), a compatibilidade entre teoria da acumulação de Steuart e esse princípio tem como base: 1) o autor não considerar que a expansão do investimento, baseada no emprego da poupança, obtida a partir dos lucros, seja o mecanismo único de geração de acumulação; e 2) sua defesa de que os gastos que não criam capacidade são necessários para a manutenção do nível da demanda agregada em valor próximo ao equivalente ao uso normal da capacidade instalada.

$O$ fato de afirmarmos que o princípio da demanda efetiva é compatível com a teoria da acumulação de Steuart não quer dizer que esta última seja totalmente consistente com o primeiro, ou que não sejam necessários avanços em sua teoria do valor e distribuição para que ele possua um argumento teórico completo que sustente sua teoria da acumulação. De fato, nossa análise se baseou nas noções mais gerais ou nos 
princípios mínimos necessários para associar o princípio da demanda efetiva ao argumento clássico. Essa alternativa não é, como já mencionamos, a única; portanto, permanecerá a dúvida se é uma interpretação benevolente do autor.

$\mathrm{Na}$ nossa interpretação, a ausência de uma teoria da taxa de lucro obrigou Steuart a desenvolver uma análise sobre acumulação que estivesse livre da necessidade de transformar lucros em investimento para garantir o crescimento, conforme fizeram os clássicos de sua época e aqueles que os sucederam. Foi também isso que, analiticamente, determinou no seu esquema a autonomia de parte dos gastos em relação à renda. Sabemos que é possível estabelecer parte importante dos padrões de gasto (com consumo ou com investimento) da economia sem conhecer a taxa de lucro. É fato também que a renda dos capitalistas depende da taxa de lucro, e que o lucro é o grande objetivo do sistema capitalista. Todavia, a análise econômica posterior aos trabalhos de Keynes (1936) e Kalecki (1933) foi capaz de estabelecer que existe uma parte importante dos gastos que são autônomos em relação à renda, o que revalida boa parte do argumento de Steuart. Esse autor concebe a determinação do nível de produto centrada fundamentalmente no estabelecimento de um padrão de consumo que é exógeno em larga medida e independente da renda, na medida em que é o oriundo do "plano" do governante. O investimento também é uma decorrência desse padrão.

Finalmente, podemos dizer que, se o estudo do valor e da distribuição na forma clássica deixa em aberto a questão da determinação dos níveis normais de produto e emprego, Steuart segue os clássicos. Contudo, além dessa abertura, a teoria de Steuart ainda possui uma lacuna na própria teoria da distribuição. A ausência de uma classe de capitalistas em sua estrutura social não o obrigou a desenvolver uma teoria dos lucros que fosse além da noção de existência de um ganho produtivo que não derivasse exclusivamente da terra, como faziam os fisiocratas. A solução inovadora de Steuart, para a descrição do processo de acumulação, foi fruto de um esforço de observação importante da dinâmica econômica, na ausência do papel dinâmico da taxa de lucro e por isso foi além do limite de raciocínio clássico marcado pela lei de Say.

\section{8_Conclusão}

Propusemo-nos a apresentar as possibilidades que se abrem para o pensamento heterodoxo com base na obra de Steuart. $\mathrm{O}$ estudo conclui visando a identificar 
uma dualidade na obra de Steuart, sublinhada pela ausência de uma teoria da taxa de lucro e o tratamento específico e necessário que atribuiu ao papel do Estado no desenvolvimento econômico. Grande destaque foi dado à intervenção do Estado na economia, na medida em que esse é um fator distintivo de Steuart em relação aos seus contemporâneos e sucessores. O Estado steuartiano é e deve ser forte, além de ser o único capaz de organizar os interesses individuais em torno de um plano econômico singular.

Não pretendemos elaborar uma interpretação que o coloque acima de seu real valor e contribuição teórica, mas construímos uma análise fundamentada por argumentos dos mais renomados autores sraffianos e interpretadores de Steuart para formular um questionamento próprio sobre a obra desse autor tão interessante e tão pouco estudado.

Vamos concluir, mais uma vez, a fim de recomendar a análise mais cuidadosa do trabalho de James Steuart. Além das questões da acumulação, do valor e da distribuição, James Steuart tratou de vários outros temas como população, moeda, bancos e comércio exterior. E sua interpretação, tão preocupada com a verificação das hipóteses teóricas pela realidade, construiu-se articulando cada um desses temas com a estrutura de pensamento apresentada nos dois primeiros livros dos Principles, demonstrando o que já estava claro em seu prefácio: o compromisso de Steuart com um método científico na intenção de criar uma explicação da economia baseada em princípios gerais, mas sem deixar de lado a referência do mundo real. Além disso, pareceu-nos ainda relevante destacar outra questão fundamental em sua obra que abre espaço para o pensamento heterodoxo atual: a articulação entre o autointeresse e o papel do Estado em Steuart como um projeto alternativo do ponto de vista da perspectiva científica do seu tempo.

Não foi nosso objetivo esgotar qualquer uma dessas questões. Ao contrário, pretendeu-se apresentá-las para atualizar a discussão na história do pensamento econômico e na economia em geral com ideias e questões "esquecidas" de economistas mortos, trazendo novamente à tona que a visão de mundo e a concepção de ciência de cada autor é fundamental para compreender sua efetiva contribuição à economia política. 


\section{Referências bibliográficas}

ASPROMOURGOS, T. On the origin of classical economics, distribution and value from William Petty to Adam Smith. Routlegde, London, 1996.

ASPROMOURGOS, T. Review on R. Tortajada. (Ed.). The Economics of James Steuart. European Journal of History of Economic Thought, v. 7, n. 2, 2000 .

BLAUG, M. David Hume (17111776) e James Steuart (1712-1780). Coleção Pioneers in Economics, n. 11, Edward Elgar, 1991.

CHAMLEY, P. Sir James Steuart inspirateur de la Théorie Générale. Revue d'économie politique, n. 3, Paris, 1962.

CHAMLEY, P. Économie politique et philosophie chez Steuart et Hegel. Paris: Dalloz, 1963.

CHAMLEY, P. Documents relatifs à Sir James Steuart. Paris, 1965a.

EAGLY, R. V. Sir James Steuart and the Aspiration Effect. Economica, n. $28,1961$.

EGE, R. The new interpretation of Steuart by Paul Chamley. In: TORTAJADA, R. (Ed.). The Economics of James Steuart. Routledge, 1999.
GAREGNANI, P. Two routes to effetive demand: a comment on Kregel. In: KREGEL, J. (Ed). Distribution, Effective Demand and International Economic Relation. Macmillan,1983.

GISLAN, J-J. James Steuart: Economy and population. In: TORTAJADA, R. (Org.). The Economics of James Steuart. Routledge, London, 1999.

KALECKI, M. (1933). Esboço de uma teoria do ciclo econômico. In: KALECKI, M. Crescimento e ciclo das economias capitalistas: ensaios selecionados e traduzidos por Jorge Miglioli. Hucitec, 1977.

KEYNES, J. M. A teoria geral do emprego, do juro e da moeda. Nova Cultural, 1985. (Coleção Os Economistas)

KOBAYASHI, N. On the method of Sir James Steuart. In: TORTAJADA, R. (Org.). The Economics of James Steuart. Routledge, London, 1999.

MALTA, M. A Teoria da Acumulação de James Steuart. 2001. Dissertação (Mestrado), IE/UFRJ, Rio de Janeiro, 2001
MALTA, M. James Steuart e o princípio da demanda efetiva. In: CONGRESSO BRASILEIRO DE HISTÓRIA ECONÔMICA, 6, 2005. Anais... Conservatória, 2005a.

MALTA, M. Controvérsias sobre a teoria da acumulacão de James Steuart. 2005. Tese (Doutorado) Universidade Federal Fluminense, Rio de Janeiro, 2005b.

MARX, K. Para a crítica da economia política. São Paulo: Nova Cultural, 2005. (Coleção Os Pensadores).

MEEK, R. The Economics of control prefigured by Sir James Steuart. Science and Society, v. 22 n. $4,1958$.

MEEK, R. Economia e ideologia. Rio de Janeiro: Zahar, 1971.

PORTO CARREIRO, C. H.

História do pensamento econômico. Rio de Janeiro: Editora Rio, 1975.

REDMAN, D. Sir James Steuart's Statateman Revisited in the light of the continental influnence. Scottish Journal of Political Economy, v. 43, n. 1, p. 48-70, Feb. 1996.

RICARDO, D. Princípios de Economia Política e Tributação. Versão de P. Sraffa (1951). Nova Cultural, 1986. (Coleção Os Economistas).
ROLL, E. História das doutrinas econômicas. São Paulo: Companhia Editora Nacional, 1948.

SAMUELS, W.; BIDDLE, J.; DAVIS, J. (Eds.). A companion to the History of Economic Thought. Blackwell: Blackwell Publishing, 2003.

SEN, S. R. Sir James Steuart's general theory of employment, interest and mone. Economica, n. $14,1947$.

SILVEIRA, A. M. Estudos sobre a Indeterminação de Sênior, Ensaios Econômicos, EPGE, v. 2, 1994.

SILVEIRA, A. M. A

indeterminação de sênior: perspectivas e realizações de um programa de pesquisa. Economia, Curitiba, n. 23, 1999.

SKINNER, A. S. Economics and the problem of the method: an eigthteen century view. Scottish Journal of Political Economy, v. 12, n. 3, Nov. 1965.

SKINNER, A. S. Introduction: Sir James Steuart and the Jacobite connection. In: TORTAJADA, R. (Ed.). The Economics of James Steuart. Routledge, 1999. 
SMITH, A. A riqueza das nacōes. Nova Cultural, 1986. (Coleção Os Economistas).

SRAFFA, P. Production of commodities by means of commodities - Prelude to a Critic of Economic Theory.

Cambridge University Press, 1960.

STEUART, J. An inquiry into the principles of political economy. Printed for A. Millar, and T. Cadell, Strand, London, 1767.

STEUART, J. The works, political metaphysical, and cronological, of the late SirJames Steuart of Coltness, Bart. T.Cadell e W. Davies, Strand, London, 1805.

STETTNER, W. F.; Sir James Steuart on the Public Debt, Quartely Journal of Economics, n. 59, May 1945.

TORTAJADA, R. Rate of interest, profit and prices in the economics of James Steuart. In: TORTAJADA, R. (Org.). The

Economics of James Stenart. Routledge, London, 1999.

YANG, H-S. The political economy of trade and growth, an analytical interpretation of Sir James Steuart's inquiry. Edward Elgar, 1994.

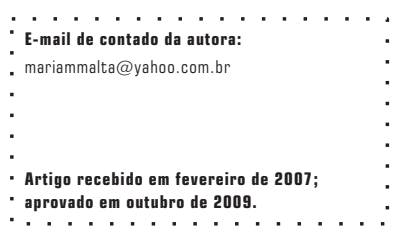


